\title{
Is bronchoscopic photodynamic therapy a therapeutic option in lung cancer?
}

\author{
K. Moghissi, K. Dixon
}

Is bronchoscopic photodynamic therapy a therapeutic option in lung cancer? K. Moghissi, K. Dixon. C ERS Journals Ltd 2003.

ABSTRACT: This study addresses whether photodynamic therapy (PDT) is a valid therapeutic option in lung cancer treatment.

A total of 24 articles were reviewed in two categories: advanced (G1) and early (G2) disease. Details considered included the following: 1) number of patients in each series; 2) staging; 3) methodology; 4) mortality; 5) morbidity; 6) survival; 7) relief of symptoms; and 8) concomitant treatments. G1 (636 patients) had severe endobronchial obstructive cancer and PDT was primarily for symptom relief. G2 (517 patients) had early stage cancer and were treated with PDT for curative intent.

There was no procedure-related mortality in either group. G1 had a 5-28\% incidence of skin sensitivity. Haemoptysis occurred in two series; one fatal, an incidence of $2.2 \%$. Almost all patients had symptomatic relief. Patients with lower disease stage and better performance status had improved survival rates. G2 had a 8-28\% incidence of sunburn. Three patients in one series (38 patients) had haemoptysis. Survival after 5 yrs in complete remission/response patients was $70 \%$.

This review suggests that bronchoscopic photodynamic therapy has indications in selected lung cancer patients with early or advanced stage disease. However, in the absence of a formal comparative study, no claim can be made of its superiority over other endobronchial therapies.

Eur Respir J 2003; 22: 535-541.
Section of Cardiothoracic Surgery, the Yorkshire Laser Centre, Goole, East Yorkshire, UK.

Correspondence: K. Moghissi, The Yorkshire Laser Centre, Goole and District Hospital, Woodland Avenue, Goole, East Yorkshire, DN14 6RX UK.

Fax: 4401724290456

E-mail: kmoghissi@yorkshirelasercentre.org

Keywords: Literature review

lung cancer

photodynamic therapy

Received: January 152003

Accepted after revision: April 142003
In 1978 DougherTy et al. [1] demonstrated that the interaction between absorbed light and haematoporphyrin derivative (HPD) photosensitiser administered and retained in cancer tissue brings about necrosis of tumours and that this photodynamic therapy (PDT) is effective in the treatment of a variety of malignant tumours.

In the case of lung cancer, PDT refers to the endoscopic treatment of tumour, the location and extent of which is first assessed bronchoscopically. A photosensitiser is then administered to the patient by i.v. injection. This is followed, after an interval, by illumination of the presensitised tumour by an appropriate laser light, which is delivered to the target tissue via an optical fibre through the bronchoscope. The light and chemical interaction leads to necrosis of the tumour.

Using the above principle, after experimental and preclinical work, KATO [2] used PDT for the first time in 1980 to treat a patient with early lung cancer who refused surgical intervention. Following bronchoscopic PDT, the patient had complete remission (CR) for 4 yrs and died later from a noncancer related cause.

The last 20 yrs has seen many publications on PDT for lung cancer showing its therapeutic usefulness in different stages of the disease. In spite of this, in Europe at least, PDT has not become a mainstream lung cancer treatment option even though there is desperate need for newer therapeutic methods other than the traditional trio of surgery, radiotherapy and chemotherapy. It is generally acknowledged that surgical and oncological advances over the past 40-50 yrs

For editorial comments see page 399. have had little impact on either early detection, resection rate or on survival of lung cancer patients.

With this background the authors undertook a review of the literature to evaluate the current state of PDT and to discuss the place of PDT for lung cancer treatment within the overall therapeutic options.

\section{Material and methods}

A literature search was made through Medline (PubMed) for listed articles on PDT in broncho-pulmonary cancer. In addition, some of the original early articles from the 1970s and published reports that were not cited in PubMed were obtained through medical libraries. In the first instance, from the abstracts of the articles, the following were excluded from the study: 1) review articles without personal experience of the authors; 2) single case report articles; 3) articles where the abstract was not published in English; and 4) articles published on the subject by the same group of investigators in different journals that appeared to comprise the same patient population. In such cases only the latest updated publication was included in this study. Only original articles concerned with PDT in lung cancer that comprised of a series of five or more patients were selected for review.

The earliest article that qualified for inclusion was published in 1984 [3] and the latest was dated 2003.

Having selected the articles, details were extracted relating to the following: 1) number of patients in the series; 2) characteristics of patients, notably stage of disease i.e. 
advanced or early stage; 3) methodology (photosensitiser, light characteristics and PDT details); 4) mortality, morbidity, including photosensitivity reaction (sunburn), and survival; and 5) concomitant pre- and/or post-PDT adjuvant treatment.

The reviewed articles fell into two categories according to the stage of disease of the treated population, as indicated by the authors. Category 1 comprised articles concerned with patients with advanced stage disease (G1, table 1); usually stages III and IV of Tumour, Node, Metastases (TNM) classification who were inoperable due to the extent of the cancer. Category 2 comprised articles related to treatment of patients with early stage disease (G2, table 2) principally tumour in situ (TIS), stage I of TNM classification, mostly inoperable due to the poor general and/or cardiovascular status of the patient.

It should be noted that some of the articles included patients with early as well as advanced disease in almost equal proportions. These were placed in both categories. Also, a few articles in category 1 included a small number of patients with early stage disease who were inoperable due to unsuitability for resectional surgery. Although these were not specifically considered with early stage disease categories, they are referred to in the discussion, when relevant.

Each article is given a number, which serves as its identification for citation in the text, the tables and bibliography [2-25]. Methodology related to the details of patient assessment, photosensitisers, laser light and instrumentation were generally similar in both groups and are dealt with together. However, results of the reviewed articles are presented separately for the patients in $\mathrm{G} 1$ and $\mathrm{G} 2$, respectively.

\section{Prephotodynamic therapy patient assessment}

In all cases standard work-up of patients had been carried out prior to PDT. This included staging procedure, histological typing of the cancer and recording of the bronchoscopic extent of tumour and severity of the endoluminal obstruction. In most series there were a number of patients who received chemo/radiotherapy prior to PDT.

\section{Photosensitiser}

The overall majority of investigators used HPD in the initial phase of PDT in the early 1980s and porfirmer sodium (Photofrin $^{\mathrm{TM}}$ ) later in the $1990 \mathrm{~s}$. The drug dose was variable during the early days of PDT. Later publications show that the standard dose became $2 \mathrm{mg} \cdot \mathrm{kg}^{-1} \cdot \mathrm{bw}^{-1}$.

A small number of patients in one series used 5aminolevulinic acid (ALA) [25].

The interval between the injection of photosensitiser and illumination was generally $48-72 \mathrm{~h}$. Some authors applied

Table 1.-Photodynamic therapy (PDT) details of 12 articles (636 patients) concerned with advanced stage lung cancer

\begin{tabular}{|c|c|c|c|c|c|c|}
\hline [Ref no.] & Patients $n$ & $\underset{\mathrm{mg} \cdot \mathrm{kg}^{-1} \cdot \mathrm{bw}^{-1}}{\operatorname{Drug}}$ & $\begin{array}{l}\text { Laser wave length } \\
\mathrm{nm} \cdot \text { dose }^{-1} \cdot \mathrm{j}^{-1} \cdot \mathrm{cm}^{-1}\end{array}$ & $\begin{array}{l}\text { Mortality } \\
\text { n (\%) }\end{array}$ & $\begin{array}{l}\text { Complications } \\
\mathrm{n}(\%)\end{array}$ & Remarks \\
\hline \multirow[t]{2}{*}[2]{$^{\#}$} & $111 \mathrm{~A}$ & HPD $2 \mathrm{mg}$ & $630 \geqslant 100$ & None & $\begin{array}{l}\text { Sunburn } \\
23(21.5)\end{array}$ & $\begin{array}{l}\text { PDT } \rightarrow \text { downstaging } \rightarrow \text { resection } \\
\text { in some patients }\end{array}$ \\
\hline & $140 \mathrm{E}$ & $\mathrm{PhF}$ & & & & 11 patients with SCLC \\
\hline \multirow[t]{2}{*}{ [3] } & 22 & HPD $3 \mathrm{mg}$ & $630(200+20)$ & None & $\begin{array}{l}\text { Pneumothorax } \\
2(9)\end{array}$ & Routine debridement day $2-4$ \\
\hline & & & & & $\begin{array}{l}\text { Pneumonia } \\
3(13)\end{array}$ & $\begin{array}{l}\mathrm{CR} \text { and } \mathrm{PR} 21 \text { patients } \\
\text { No response } 1 \text { patient }\end{array}$ \\
\hline [4] & 24 & HPD 2 & $630(200-300)$ & None & None stated & Routine debridement day $2-4$ \\
\hline [5] & 5 & $\mathrm{PhF}$ & $630(200-300)$ & None & None stated & $\begin{array}{l}\text { Routine debridement day } 2-4 \\
5 \text { PDT and EBR versus } 6 \text { EBR } \\
\text { PDT+EBR more sustained palliation }\end{array}$ \\
\hline [7] & 10 & HPD $2 \mathrm{mg}$ & $630(300)$ & None & $\begin{array}{l}\text { Sunburn } \\
2(20)\end{array}$ & Additional EBR 6 patients \\
\hline [11] & $\begin{array}{l}15 \\
11 \mathrm{YAG}\end{array}$ & $\mathrm{PhF} 2 \mathrm{mg}$ & $630(200)$ & None & No sunburn & $\begin{array}{l}\text { RT PDT } v \text { YAG } \\
\text { Routine debridement day } 4-5\end{array}$ \\
\hline [17] & 175 & HPD and DHE & $630(200)$ & $\begin{array}{l}30 \text { days } \\
8(4.5)\end{array}$ & $\begin{array}{l}\text { Fatal haemorrhage } \\
\qquad 4(2.2)\end{array}$ & $\begin{array}{l}\text { Routine debridement day } 1-3 \\
\text { Survival related to tumour stage and PS }\end{array}$ \\
\hline [18] & 17 & $\mathrm{PhF}$ II $2 \mathrm{mg}$ & $630(200)$ & None & $\begin{array}{l}\text { Sunburn } \\
(5.8)\end{array}$ & Routine debridement day $0,4-5$ \\
\hline \multirow[t]{2}{*}{ [19] } & $106 \mathrm{PDT}$ & $\mathrm{PhF} 2 \mathrm{mg}$ & $630(200)$ & None & $\begin{array}{l}\text { Sunburn } \\
\text { (20) }\end{array}$ & RMCT of PDT $v$ YAG \\
\hline & $105 \mathrm{YAG}$ & & & & $\begin{array}{l}\text { Haemoptysis } \\
\text { (18) }\end{array}$ & $\begin{array}{l}\text { At one month PDT palliation better } \\
\text { than YAG }\end{array}$ \\
\hline [21] & $14 \mathrm{PDT}$ & $\mathrm{PhF}$ & $630(200)$ & 1 in PDT & $\begin{array}{l}\text { Sunburn } \\
4(28)\end{array}$ & $\mathrm{RT}$ of PDT $v$ YAG \\
\hline [22] & $\begin{array}{l}17 \text { YAG } \\
100\end{array}$ & $\mathrm{PhF} 2 \mathrm{mg}$ & $630(200)$ & None & $\begin{array}{l}\text { Sunburn } \\
\quad(5)\end{array}$ & $\begin{array}{l}\text { Debridement day } 2 \\
\text { Survival related to tumour stage and } \\
\text { PS debridement } 3-5 \text { day } \\
\text { SCLC } 10 \text { patients }\end{array}$ \\
\hline [25] & 40 & $\begin{array}{c}\text { Photosan } \\
2 \mathrm{mg} \text { and ALA }\end{array}$ & $630(300)$ & None & None stated & $\begin{array}{l}\text { Non-RT of photosensitisers } \\
\text { (16 photosan versus } 24 \text { ALA) } \\
\text { All PDT and hyperbaric } \mathrm{O}_{2}\end{array}$ \\
\hline
\end{tabular}

A: advance disease cases; E: early disease cases; YAG: neodynium yttrium aluminium garnet laser therapy; PDT: photodynamic therapy; HPD haematoporphyrin derivative; PhF: Photofrin; DHE: dihaematoporphyrin ether; ALA: 5-aminolevulinic acid; SCLC: small-cell lung cancer; CR: complete remission; PR: partial remission; EBR: external beam radiotherapy; RT: randomised trial; RMCT: randomised multicentre trial; PS: performance status; $\mathrm{O}_{2}$ : oxygen. ${ }^{\#}$ : article with mix of early and advanced cases. 
Table 2.-Photodynamic therapy (PDT) details of 12 articles (517 patients) concerned with early stage lung cancer

\begin{tabular}{|c|c|c|c|c|c|c|}
\hline [Ref no.] & Patients/lesions $n$ & $\begin{array}{l}\text { Drug } \\
\mathrm{mg} \cdot \mathrm{kg}^{-1} \cdot \mathrm{bw}^{-1}\end{array}$ & $\begin{array}{l}\text { Laser wavelength } \\
\mathrm{nm} \cdot \text { dose }^{-1} \mathrm{j}^{-1} \cdot \mathrm{cm}^{-1}\end{array}$ & Mortality & $\begin{array}{l}\text { Complications } \\
\text { n }(\%)\end{array}$ & Remarks \\
\hline \multirow[t]{3}{*}{ [6] } & \multirow[t]{3}{*}{$38 / 40$} & \multirow{3}{*}{$\begin{array}{l}\text { HPD } \\
2-5 \mathrm{mg}\end{array}$} & \multirow[t]{3}{*}{$90-675$ or $54-600$} & \multirow[t]{3}{*}{ None } & Sunburn 3 (7.7) & Procedure under GA \\
\hline & & & & & $\begin{array}{l}\text { Respiratory complication } \\
5 \text { (13) }\end{array}$ & CR $11(29 \%)$ up to $53 \mathrm{~m}$ \\
\hline & & & & & Haemoptysis $3(7.8)$ & SCLC 1 \\
\hline \multirow[t]{3}{*}{ [8] } & \multirow[t]{3}{*}{$36 / 39$} & \multirow{3}{*}{$\begin{array}{l}\text { HPD } \\
2.5 \mathrm{mg}\end{array}$} & \multirow[t]{3}{*}{630} & \multirow[t]{3}{*}{ None } & \multirow[t]{3}{*}{ None stated } & CR $11(>30 \%)$ \\
\hline & & & & & & $\begin{array}{l}\text { Survived } 37-109 \text { months } \\
16 \text { patients }\end{array}$ \\
\hline & & & & & & Non-Ca cause 15 patients \\
\hline \multirow{2}{*}{ [9] } & \multirow[t]{2}{*}{$13 / 14$} & HPD & \multirow[t]{2}{*}{$630(200-400)$} & \multirow[t]{2}{*}{ None } & \multirow[t]{2}{*}{ None stated } & CR $10(77 \%)$ \\
\hline & & $2.5 \mathrm{mg}$ & & & & $\begin{array}{l}\text { Cancer no CR had surgery } \\
3 \text { patients }\end{array}$ \\
\hline \multirow[t]{2}{*}{ [10] } & \multirow[t]{2}{*}{$51 / 61$} & $\mathrm{PhF}$ II & \multirow[t]{2}{*}{$630(100-200)$} & \multirow[t]{2}{*}{ None } & \multirow[t]{2}{*}{ Sunburn 14 (28) } & CR $43(84.8 \%)$ for 18 months \\
\hline & & $2 \mathrm{mg}$ & & & & $\begin{array}{l}97 \% \text { CR if tumour }<1 \mathrm{~cm} \\
\text { TIS } 100 \% \text { CR } 70 \% \\
\text { survival } \geqslant 5 \text { yrs }\end{array}$ \\
\hline \multirow[t]{4}{*}{ [12] } & \multirow[t]{4}{*}{$29 / 39$} & $\mathrm{PhF}$ & \multirow[t]{4}{*}{$630(100-3000)$} & \multirow{4}{*}{$\begin{array}{l}1 \mathrm{pt} \\
30 \text { days }\end{array}$} & Anaphylatic reaction 1 & CR $19(64 \%)$ \\
\hline & & $2 \mathrm{mg}$ & & & Sunburn 12 (41) & $\mathrm{EBR}$ for $10 \mathrm{PR} \rightarrow 7 \mathrm{CR}$ \\
\hline & & & & & & 5 -yr survival $56 \%$ overall \\
\hline & & \multirow{3}{*}{$\mathrm{PhF}$} & & & & Debridement frequent (everyday) \\
\hline \multirow[t]{2}{*}{ [13] } & \multirow[t]{2}{*}{$22 / 30$} & & \multirow[t]{2}{*}{$630(200)$} & None & None stated & PDT stump recurrence $6(23 \%)$ \\
\hline & & & & & & Total CR 1 patient \\
\hline [14] & $30 / 39$ & $\mathrm{PhF}$ & $630(200)$ & None & Sunburn 4 (13) & Survival 2-95 m (median $10 \mathrm{~m})$ \\
\hline & & $2 \mathrm{mg}$ & & & & $\begin{array}{l}\text { TIS } 17 \text { with } 100 \% \text { CR } \\
\text { PDT } \rightarrow \text { EBR } 2 \text { patients }\end{array}$ \\
\hline$[15]$ & $12 / 12$ & $\mathrm{PhF}$ & 630 & None & Not stated & Tumour recurrence in stump \\
\hline & & $2 \mathrm{mg}$ & & & & PDT+Brachytherapy \\
\hline [16] & $21 / 28$ & $\mathrm{PhF}$ & $630(200-400)$ & None & Sunburn 5 (23.7) & $\begin{array}{l}\text { PDT followed by surgery } \\
10 \text { patients }\end{array}$ \\
\hline & & $2 \mathrm{mg}$ & & & & $\operatorname{CR} 11(52 \%)>12 \mathrm{~m}$ \\
\hline & & & & & & $\begin{array}{l}\text { PDT alone and spared operation } \\
9 \text { patients }\end{array}$ \\
\hline [20] & 102 & $\mathrm{PhF}$ & $630(200)$ & None & Sunburn $22(22)$ & CR $80(79 \%)>40 \% 24 \mathrm{~m}$ \\
\hline & & $2 \mathrm{mg}$ & & & $\begin{array}{l}\text { Respiratory complications } \\
20(18-22)\end{array}$ & $\begin{array}{l}\text { Median disease specific } 5.7 \text { yrs } \\
\text { Median survival } 3.5 \text { yrs }\end{array}$ \\
\hline$[2]^{\#}$ & $140 \mathrm{E}$ & $\mathrm{PhF}$ & $630(100$ or 200$)$ & None & Sunburn $30(21.5)$ & CR $77(81 \%)$ for stage I \\
\hline & $111 \mathrm{~A}$ & $2 \mathrm{mg}$ & & & & 5 -yr survival $68.4 \%$ \\
\hline & & & & & & $\begin{array}{l}5 \text {-yr disease specific } \\
\text { survival } 94.8 \%\end{array}$ \\
\hline [23] & 23 & HPD & $630(360)$ & None & None stated & CR $16(62 \%)$ \\
\hline & & $5 \mathrm{mg}$ & & & & $\begin{array}{l}\text { Additional brachytherapy } \\
3 \text { patients }\end{array}$ \\
\hline [24] & $6 \mathrm{E}$ & $\mathrm{PhF}$ & $630(200)$ & None & $\begin{array}{l}\text { Fibrous scarring and } \\
\text { stenosis after } 6 \text { months } \\
4(67)\end{array}$ & Non-RT \\
\hline & $6 \mathrm{YAG}$ & $2 \mathrm{mg}$ & & & & $\begin{array}{l}\text { Oncological/survival outcome } \\
\text { not stated }\end{array}$ \\
\hline & $17 \mathrm{EC}$ & & & & & \\
\hline
\end{tabular}

E: early disease cases; A: advance disease cases; YAG: neodynium yttrium aluminium garnet laser therapy; EC: electrocautery; HPD: haematoporphyrin derivative; PhF: photofrin; pt: patient; GA: general anaesthetic; CR: complete remission; SCLC: small cell lung cancer; Ca: cancer; TIS: tumour in situ; EBR: external beam radiotherapy; PR: partial remission; PDT: photodynamic therapy; RT: randomised trial. \#. article with mix of early and advanced cases; $`$ : patient died.

illumination from a few hours to $24 \mathrm{~h}$ after administration of the photosensitiser [17, 23].

\section{Laser light and light dosage}

Argon, various types of dye laser and, more recently, diode lasers have been used to produce red light. The majority of investigators have used red light at $\sim 630 \mathrm{~nm}$ wavelength. The power setting was $400-500 \mathrm{mw} \cdot \mathrm{cm}^{-1}$ of diffusing tip to achieve a total illumination dose of $200-300 \mathrm{j} \cdot \mathrm{cm}^{-1}$ of the tumour.

\section{Procedurelinstrumentation}

The majority of authors carry out PDT under topical anaesthesia, though some have used general anaesthesia $[6,17,18,22,24]$. All authors used a flexible fibreoptic bronchoscope for visualisation and placement of the optical fibre, which was passed through the biopsy channel of the instrument to the target tissue. Those who carried out the procedure under general anaesthesia used a rigid bronchoscope or endotracheal intubation for ventilation through which they placed the fibreoptic instrument for illumination. 
Treatment, in bulky exophytic tumours, has been interstitial, with the cylindrical diffusing tip of the optical fibre placed into the cancer tissue. Superficial surface illumination was employed for early stage tumours.

Post PDT debridement/clean up bronchoscopy has been underlined by most investigators. Some, in the presence of bulky tumours, carry out routine bronchoscopic debridement immediately after illumination and from 1-5 days later, to remove debris, mucus and fibin clot mixed with necrotic tumour $[17,22]$. Many clean up bronchoscopies were carried out with a second illumination of the residual tumour. In cases of early cancer, the majority of authors carried out debridement in order to clean up the debris and secretions.

\section{Assessment of results}

In cases with advanced disease, the results were evaluated by symptom relief, post PDT spirometric changes and percentage bronchial luminal desobliteration. The results in early stage disease were assessed by completeness of tumour elimination in response to treatment and survival. Response to treatment was judged by all authors as CR if no residual tumour was present macroscopically, or microscopically (cytology, brush, biopsy) in the treated area. Partial remission/response (PR) was defined as a macroscopic reduction in tumour size to $>50 \%$. No response was defined as tumour size reduction by $<50 \%$.

\section{Results}

\section{Group 1: patients with advanced disease}

A total of 636 patients with advanced lung cancer were treated and reported in 12 papers. The PDT details of these patients are shown in table 1 . The indication for PDT in this group was severe $(>50 \%)$ endobronchial obstructive cancer, in symptomatic patients. By design most authors have treated only nonsmall-cell cancer. However, a few patients with small-cell lung cancer were submitted to PDT with an equal success rate to that of nonsmall-cell lung cancer (NSCLC) cases $[21,23]$.

None of the reviewed series indicate procedure-related mortality. However, 30 days mortality was recorded in one larger series [17].

Skin photosensitivity (sunburn) has been referred to in most of the reviewed papers ranging 5-28\% [21, 22]. In almost all cases the severity of skin photosensitivity reaction was considered to be mild (grade 1 skin burn).

Post PDT blood staining of expectoration for a few days was noted by a number of authors. Nonfatal haemoptysis occurred in $18 \%$ of one series of 185 patients. Fatal haemorrhage was recorded in $2.2 \%$ of another series of 175 patients.

The most common complication of bronchoscopic PDT in this group relates to the respiratory system. Cough, expectoration of necrotic debris and various degrees of dyspnoea for a few days post-PDT was noted by many of the authors. Infective pneumonitis, pneumonia and atelectasis due to pulmonary collapse resulting from retention of plugs of fibrin and necrotic debris were rarely seen and usually resolved following post-PDT bronchoscopic cleaning.

Almost all patients in this group had symptom relief. The improvement was matched objectively by amelioration of ventilatory function, with relief of dyspnoea and cough. Two of the larger series of patients in this group, with a total of 275 patients, have reported that survival after PDT in patients with advanced disease depends largely on stage of disease and the patients' performance status (PS) $[17,22]$. Patients with
PS (World Health Organisation (WHO) scale) of $\geqslant 3$ [17] or those with Karnofsky $<50$ [22], had worse survival than those with better PS for similar tumour stage.

All the reviewed articles have concluded that PDT is safe and effective in providing symptom relief in patients with advanced stage disease and substantial endobronchial obstruction. In addition, symptomatic improvement is matched by the extent of bronchial desobliteration and improvement in chest radiograph image.

Comparison of photodynamic therapy and neodynium yttrium aluminium garnet laser radiation. Three articles reported the results of studies comparing PDT with neodynium yttrium aluminium garnet (Nd YAG) laser in patients with advanced lung cancer and substantial endoluminal obstruction [11, 19, 21]. These involved 267 patients randomised to PDT and $\mathrm{Nd}$ YAG laser treatment. The conclusion in all articles was that PDT and YAG laser treatment had a similar effectiveness and safety in palliation of symptoms; although the effect of YAG laser treatments was more immediate than PDT. Patients undergoing PDT had a significantly prolonged and greater symptomatic amelioration that was objectively matched by better pulmonary function and more extensive desobliteration of bronchi. There was also a general agreement that PDT was easier to perform and that there was survival benefit in the PDT subgroup, compared with YAG for similar disease stage.

Photodynamic therapy combined with other cancer treatment. Sequential YAG and PDT were carried out in a few patients in some of the series. In one pilot study bronchoscopic YAG laser treatment was used first to debulk endotracheal/endobronchial tumour in a selected group of patients [18]. PDT was applied to the residual lesion $4-6$ weeks later. Both symptomatic and survival results of patients in this study appeared superior to the results of either PDT or YAG laser therapy alone. However, the protocol of study was not concerned with comparison of combined versus individual PDT.

Photodynamic therapy and chemo-/radiotherapy. In many patients with inoperable and advanced stage disease external beam radiotherapy (EBR) had been used prior to referral for PDT. In one series $85 \%$ of patients had chemo/radiotherapy before PDT [22].

Some authors used EBR after PDT in patients when there was evidence of incomplete remission of the tumour by PDT. In one study six of the patients with very advanced disease were submitted to EBR following PDT [7]. Of these patients, three developed significant respiratory problems during and following radiation. In another study, a small number of patients were randomised to PDT versus PDT and EBR [5]. There was better overall symptomatic relief in those receiving PDT and EBR.

In at least two series a small number of patients with small-cell lung cancer received chemotherapy concomitantly with PDT with a good pathological and symptomatic response [2, 22].

\section{Group 2: photodynamic therapy in patients with early stage lung cancer}

A total of 523 patients with early stage bronchial carcinoma were treated by PDT and are reported in 13 publications (table 2). The major indication for PDT in early lung cancer was to offer potentially curative treatment to patients with early stage cancer who were considered in the category of high surgical risk, or who refused operation. Some patients were treated by PDT because surgical resection may have resulted in poor quality of life after a successful operation. An 
alternative indication was bronchial stump recurrence [15]. PDT was offered to the small number of patients with superficial cancer, as an alternative to surgery $[2,16]$.

No procedure-related death occurred in any of the series in G2 patients. However, there were a number of PDT-related complications in some series, which included the following: 1) The incidence of skin burn/photosensitivity of mild degree was reported to be 7.7-28\% [6, 10]; 2) Expectoration of debris and excessive bronchial secretion for a few days after PDT has been a fairly common occurrence. Airway obstruction was reported in two cases in one series of 29 patients [12]. Serious haemoptysis was reported in three of the 38 patients presented by EDELL and CORTESE [6]. Nevertheless, no haemorrhagic complications were recorded in two larger series with a total of 242 patients [2, 20]; 3) Tumour response to treatment is recorded as CR in $>70 \%$ of 331 patients $[2,9$, $10,20]$. In some cases $C R$ reached $90 \%$ either through additional treatment, such as radiotherapy, or through more careful and precise selection of patients with early stage cancer. Long-term (5-yr) survival amongst patients with TIS and stage 1, who responded fully to treatment, has been $\sim 70 \%$ [2]. When death from causes other than cancer was eliminated 5-yr survival of $90 \%$ was recorded in treatment of TIS tumours [2]; 4) PDT in bronchial stump recurrence of cancer was reported in three series [2, 3, 15]. LAM [13] found that three of the five patients with recurrence of cancer at the bronchial stump who initially responded to PDT had tumour recurrence. This has not been observed in other series [2, 15], whose overall results were favourable to excellent.

In one report a comparative study was made to evaluate post-treatment local pathological sequellae of bronchial wall healing in 29 patients (15 with early stage superficial squamous cell carcinoma and 14 with typical carcinoid) [24]. Six patients had bronchoscopic PDT and the remaining 23 had bronchoscopic Nd YAG laser $(n=6)$ or Electrocautery (EC; $n=17)$, respectively. The authors found substantially more pronounced airway scarring and significant bronchial stenosis in the PDT group $(4 / 6=67 \%)$, compared with $\mathrm{Nd} \mathrm{Yag}$ (83\% scarring and $17 \%$ stenosis) or EC $(29 \%$ scarring and $7 \%$ stenosis). However, the study was nonrandomised and suffered from a lack of indication of selection criteria of allocation to different groups of treatment and variation in histological types. Furthermore, the mean period of follow-up was 6 months and the oncological outcome was not reported.

\section{Discussion}

It is generally acknowledged that surgical resection is the first choice treatment for those patients with lung cancer where their general and oncological condition permits this. However, in the absence of a lung cancer detection programme, at presentation many sufferers are in an advanced stage of the disease with an unresectable tumour. It follows that only a small minority of a large population will be offered, or will benefit from surgery. Considering that some operated patients will also have recurrence of their disease, it becomes clear that for an overwhelming majority of lung cancer patients some form of therapy other than surgical resection will be required. Clinically, oncologically and from the therapeutic perspective, the nonsurgical patient population falls into two subgroups. In one subgroup are those who, from personal choice or poor general clinical condition, cannot be offered surgical treatment though they have localised and oncologically early disease within their bronchial tree. The second patient subgroup includes those with oncologically inoperable and surgically unresectable cancer because of their advanced disease.
These two subgroups have remained a therapeutic challenge to physicians and surgeons alike and naturally have constituted the primary target for PDT, as well as other endobronchial therapy, such as $\mathrm{Nd}$ YAG laser, EC, cryotherapy and brachytherapy. It should be emphasised that, to date, there has been no randomised comparative study to evaluate the relative efficacy and treatment outcome of these different therapies for cases with early or advanced disease. Therefore, it follows that many interventional bronchoscopy units carry out methods that they are more accustomed to. As such, there is no evidence-based consensus on the relative value of the individual procedure compared with the alternatives. However, there have been a few trials comparing bronchoscopic PDT and Nd YAG laser application in patients with advanced disease with substantial endobronchial obstruction, to which reference has been made $[11,19,21]$. There has also been one nonrandomised study to evaluate the pathological healing sequellae with PDT, Nd YAG and EC therapy in patients with early stage lung cancer, previously referred to [24]. In another review article based on meta-analysis the authors reviewed evidence for the use of PDT, brachytherapy, electrocautery, cryotherapy and Nd YAG laser therapy as treatment options in the management of early lung cancer [26]. Based on the level of evidence and benefit, the authors made graded recommendations that indicated PDT as grade B, electrocautery, brachytherapy and cryotherapy as grade $\mathrm{C}$ and $\mathrm{Nd}$ YAG laser therapy as the least recommended treatment.

This review of 24 articles covering 1159 patients and extending over a period of 18 yrs shows that bronchoscopic PDT has been thought by many throughout the world to have an important therapeutic role in both subgroups of patients, provided that tumours can be identified bronchoscopically. Although, because of referral patterns, almost all studies were concerned with NSCLC, PDT has also been shown to be effective in the treatment of small cell histological type cancer $[2,22]$. However, it is relevant to draw attention to the fact that since PDT is dependent on the interaction between a chemical photosensitiser (drug) and light of an appropriate wavelength (in the presence of oxygen) its effect is subject to a number of variables. These include the type and dose of the drug, the time required from its administration to its therapeutic dose retention in target tissues, the type and dose of the light and its transmission through normal and abnormal tissues. These factors are responsible for an apparent variation in PDT methods by different authors, which is partly reflected on table 1 and 2 . Nevertheless, there is now some measure of agreement amongst the practitioners and hence standardisation, at least for Photofrin (Porfimer Sodium), which is currently the licensed drug most commonly used for broncho-pulmonary cancer. This is reflected in the most recent publications and is presented in table 1 and 2 .

In early stage disease the role of PDT is one of curative intent. Detailed analysis of table 2 articles suggests that, in the presence of early stage cancer (TIS and stage I), CR of variable duration was achieved in the overwhelming majority of patients. In some cases $\mathrm{CR}$ was of long duration amounting to cure of the disease. In EDELL et al. [6] in a series of 38 patients, CR lasted for 54 months for over one third of patients. The Japanese experience [2, 27] suggests CR of $>90 \%$ can be expected in those early cancers where the tumour size is $<1 \mathrm{~cm}$. In such patients post-PDT survival appears comparable to surgical resection at a similar stage. In this context it is important to note that the notion of CR refers to the local effect of therapy and is much dependent on the time at which a patient had been examined bronchoscopically. However, it reflects the effect of treatment in function of time (duration), which in turn is dependent on the initial accuracy of the evaluation of extent and depth of the lesion 
by the clinician as well as the effectiveness of the light dose and its transmission. Therefore, the authors believe that in the interpretation of the significance of $\mathrm{CR}$ and its overall duration, one should take account of the above consideration. Similarly, the authors suggest that pathological sequellae of PDT, such as pronounced fibrous scarring [24], should be looked at in the light of accuracy of the pretreatment evaluation of the disease, as well as the drug and light dose. This evaluation and definition of depth of tumour involvement is one of the problems related to the treatment of superficial early cancer. Recent progress in endobronchial ultrasonography (EBUS) suggests that the method may be usefully deployed in planning PDT and assessing results [28].

A number of authors have drawn attention to the fact that in some patients with early cancer the disease is not confined to a single segmental/lobar bronchus but extends proximally or distally to more than one segment, sometimes to the opposite lung. This accounts for the fact that in some series the number of lesions is in excess of the number of patients (table 2). In a few of these patients surgical resection may be possible but at the expense of a wide excision and loss of significant healthy pulmonary parenchyma. Such cases constitute major indications of PDT either as a sole modality treatment or as a preliminary to pulmonary resection when post-PDT extent of the cancer is reduced allowing less extensive operation $[9,21,27]$. The monitoring of early cancer patients who are, or may become, suitable for surgery but are treated with PDT is of paramount importance, as illustrated by EDELL and CORTESE [9]. These authors treated 13 patients with early cancer of whom $10(77 \%)$ had CR. The remaining three patients, in whom $\mathrm{CR}$ was shown by monitoring not to be sustained, were submitted to surgical resection with a successful outcome. In this regard it is relevant to note that mapping of the location and extent of the bronchial mucosal involvement by the cancer is mandatory for accurate targeting and illumination of the lesion. Also, such mapping in early bronchogenic cancer may not be complete or precise by standard white light bronchoscopy. Fluorescence bronchoscopy utilising blue light (440 nm wavelength) can enhance the diagnostic accuracy and definition of the extent of TIS and intra-epithelial cancer within the bronchi [29].

An important area, which has attracted the attention of some investigators, is that of bronchial stump recurrence after pulmonary resection. Whilst a few series contain a small number of such patients treated using PDT with success $[13,15]$, a large series report would be desirable. Both EBUS and fluorescence bronchoscopy may be used in order to determine extent and depth of stump infiltration and recurrence [28, 29].

Analysis of articles concerned with PDT in advanced stage disease (table 1) shows some important points relevant to this category of patients who form $80-85 \%$ of the lung cancer population. Many of the patients in this group had already been submitted to chemo/radiotherapy with persistence or local endobronchial recurrence of the tumour. PDT appears to have been effective in achieving local PR/CR of the tumour with improvement of patient symptoms, notably dyspnoea, in most cases. The review indicates no evidence of incompatibility between PDT and chemo/radiotherapy. It also indicates that, in advanced cases with major endo-luminal bronchial obstruction, PDT is as effective as thermal laser treatment, with the added advantage of a more sustained result. Furthermore, there is some evidence of the benefit of using sequential YAG laser and PDT [18]. Nevertheless, it should be re-emphasised that purely from the debulking point of view, Nd YAG laser immediately achieves the objective of bronchial desobliteration, which is not the case with PDT. It is also relevant to again underline the lack of randomisation in the study to compare and contrast the effects of the main endoluminal therapy methods (PDT, Nd YAG, EC, cryotherapy and brachytherapy). In advanced disease this means that no one therapy can claim superiority of outcome over another.

A practical point that emerges from two of the articles in G1 patients of this review [17, 22] concerned with 275 patients is the influence of PS and metastatic (stage IV) disease on survival. In fact, in one of these articles $40 \%$ of patients with better WHO scale, $(<2)$ had a 2 yrs survival versus $5 \%$ for those with PS of $>2$, which was statistically significant [22]. This suggests that such patients should not be considered for PDT.

None of the articles in this review have referred to the issue of cost. This may be due to the fact that until recently, none of the photosensitisers (drugs) were licensed and, therefore, much of the cost was absorbed by research grants. The licensing of at least one drug (Photofrin) both by the Food and Drug Agency (FDA) and European Union (EU) authorities means that the drugs have to be paid for by the health authorities and, consequently, PDT is considered by many centres as prohibitively expensive compared with some of the other endobronchial procedures. However, thus far, no study of the cost of PDT compared with other endoluminal procedures has been carried out. Nevertheless, in the present climate of "value-for-money" attitude in healthcare, the issue of cost will have to be addressed by a proper controlled study.

From the start, porphyrin derivatives, notably HPD and Photofrin, were the most frequently used photosensitisers, with the activating laser light within the $630 \mathrm{~nm}$ range of red light. In recent years, since the licensing of Photofrin for the treatment of advanced lung cancer use by the FDA and EU licensing bodies, this drug has become the photosensitiser of choice. It is important to note that other unlicensed photosensitisers have been used in endoscopic PDT for lung cancer but both infrequently and in a small number of cases. Tetra (m-hydroxyphenyl) chlorine has been used by some [30] but no conclusion can be drawn from published literature because of the lack of precise information related specifically to its use in lung cancer. Systemic ALA has only been tried in one small series [25]. At the present time the number of lung cancer patients in whom drugs other than Photofrin have been used is too small for conclusions to be drawn regarding their safety or efficacy in endoscopic bronchial cancer situations.

Review of the articles concerned with PDT in early and advanced disease (table 1 and table 2 ) indicates a wide range in the incidence of skin photosensitivity reaction (sunburn). This can be a prohibiting factor in the use of PDT. However, experience and analysis of recent work, to which reference is already made, suggests that those patients among the advanced stage disease group (stage IV) and/or with poor PS should not be referred to PDT [17, 22]. In addition, the sunburn complication can be reduced considerably by active counselling of patients and thorough staff education [17].

\section{Conclusion}

This review indicates that bronchoscopic PDT is both safe and beneficial to lung cancer patients whose tumours can be identified and accessed bronchoscopically.

In advanced stage disease PDT is a treatment option for palliation and relief of symptoms in those patients with major airway obstruction. It can also be used combined with radiotherapy and/or chemotherapy or thermal laser (YAG). 
Selection of patients is important and requires sound judgement. Those with metastatic disease and poor PS should, in preference, receive other endobronchial therapies, such as $\mathrm{Nd}$ YAG laser.

In early stage lung cancer bronchoscopic PDT appears to be the treatment of choice for the following: 1) those that are unsuitable for surgical resection or refuse operation; 2) bronchial stump tumour infiltration or recurrence; and 3) patients with multiple site cancer.

PDT may also have a place for some patients with extensive superficial bronchial cancer in conjunction with surgical resection.

This review provides sufficient evidence that photodynamic therapy is an effective and valuable lung cancer treatment and should be considered as one of the therapeutic options of this disease. However, it should be understood that, as yet, there is a lack of evidence based on prospective randomised study regarding photodynamic therapy in comparison with other endobronchial therapeutic methods and, therefore, there is no consensus of opinion as to the relative value of endoscopic photodynamic therapy compared with other endobronchial therapies.

\section{References}

1. Dougherty TJ, Kaufman JE, Goldfarb A, Weishaupt KR, Bouyle DG, Mitleman A. Photoradiation for the treatment of malignant tumours. Cancer Res 1978; 38: 2628-2635.

2. Kato H. Photodynamic therapy for lung cancer - A review of 19 years experience. $J$ Photochem Photobiol B Biol 1998; 42: 96-99.

3. Balchum OJ, Doiron DR, Huth GC. PDT of endobronchial lung cancer employing the photodynamic action of the Haematoporphyrin Derivative. Lasers Surg Med 1984; 14: 13-30.

4. Lam S, Muller NL, Miller RR, et al. Predicting the response of obstructive endobronchial tumours to PDT. Cancer 1986; 58: 2298-2306.

5. Lam S, Kostashuk EC, Coy EP, Laukkanen E, LeRiche JC, Mueller HA. A randomised study of the safety and efficacy of photodynamic therapy using photofrin II combined with palliative radiotherapy versus palliative radiotherapy alone in patients with inoperable obstructive non-small cell bronchogenic carcinoma. Photochem Photobiol 1987; 46: 893-897.

6. Edell ES, Cortese DA. Bronchoscopic Phototherapy with Hematoporphyrin Derivative for Treatment of Localized Bronchogenic Carcinoma. A 5-year experience. Mayo Clin Proc 1987; 14: 62-68.

7. LoCicero J, Metzdorff M, Almgren C. Photodynamic therapy in the palliation of late stage obstructing non-small cell lung cancer. Chest 1990; 98: 97-100.

8. Ono R, Ikeda S, Suemasu K. Hematoporphyrin derivative photodynamic therapy in roentgenographically occult carcinoma of the tracheobronchial tree. Cancer 1992; 69: 16961701.

9. Edell ES, Cortese DA. Photodynamic therapy in the management of early superficial squamous cell carcinoma as an alternative to surgical resection. Chest 1992; 102: 13191322 .

10. Furuse K, Fukuoka M, Kato H, et al. A prospective phase II study on photodynamic therapy with photofrin II for centrally located early-stage lung cancer. The Japan Lung Cancer Photodynamic Therapy Study Group. J Clin Oncol 1993; 11: 1852-1857.

11. Moghissi K, Dixon K, Parsons RJ. Controlled trial of NdYAG laser versus Photodynamic therapy for advanced malignant bronchial obstruction. Lasers Med Sci 1993; 8: 269-273.

12. Imamura S, Kusunoki $\mathrm{Y}$, Takifuji $\mathrm{N}$, et al. Photodynamic therapy and/or external beam radiation therapy for roentgenologically occult lung cancer. Cancer 1994; 73: 16081614.

13. Lam S. Photodynamic therapy of lung cancer. Semin Oncol 1994: 21: 15-19.

14. Sutedja G, Lam S, LeRiche JC, Postmus PE. Response and pattern of failure after photodynamic therapy for intraluminal stage I lung cancer. Journal of Bronchology 1994; 1: 295298.

15. Freitag L, Korupp A, Itzigehl I, et al. Experiences with fluorescence diagnosis and photodynamic therapy in a multimodality therapy concept of operated, recurrent bronchial carcinoma. Pneumologie 1996; 50: 693-699.

16. Cortese DA, Edell ES, Kinsey JH. Photodynamic therapy for early stage squamous cell carcinoma of the lung. Mayo Clin Proc 1997; 72: 595-602.

17. McCaughan JS Jnr, Wiliams TE. Photodynamic therapy for endobronchial malignant disease: A prospective fourteenyear study. J Thorac Cardiovasc Surg 1997; 114: 940-947.

18. Moghissi K, Dixon K, Hudson E, Stringer M, Brown S. Endoscopic laser therapy in malignant tracheo bronchial obstruction using sequential NdYAG laser and photodynamic therapy. Thorax 1997; 52: 281-283.

19. Weiman TJ, Diaz-Jimenez JP, Moghissi K, et al. Photodynamic therapy (PDT) with photofrin is effective in the palliation of obstructive endobronchial lung cancer: results of two randomised trials (abstract). Proceedings of the 34th annual meeting of the American Society of Clinical Oncology, 16-19 May 1998, Los Angeles, CA, USA.

20. Lam S, Haussinger K, Leroy M, Sutedja T, Huber RM. Photodynamic therapy (PDT) with photofrin, a treatment with curative potential for early-stage superficial lung cancer (abstract). Proceedings of the 34th annual meeting of the American Society of Clinical Oncology, 16-19 May 1998, Los Angeles, CA, USA.

21. Diaz-Jimenez JP, Martinez-Ballarin JE, Llunell A, Farrero E, Rodriguez A, Castro MJ. Efficacy and safety of photodynamic therapy versus Nd-YAG laser resection in NSCLC with airway obstruction. Eur Respir J 1999; 14: 800-805.

22. Moghissi K, Dixon K, Stringer M, Freeman T, Thorpe A, Brown $\mathrm{S}$. The place of bronchoscopic photodynamic therapy in advanced unresectable lung cancer: experience 100 cases. Eur J Cardiothorac Surg 1999; 15: 1-6.

23. Patelli M, Lazzari Agli L, Poletti V, Falcone F. Photodynamic laser therapy for the treatment of early-stage bronchogenic carcinoma. Monaldi Arch Chest Dis 1999; 54: 315-318.

24. Van Boxem AJM, Westerga J, Wenmans BJW, Postmus PE, Sutedja G. Photodynamic Therapy, NdYAG laser and electro cautery for treating early stage intraluminal cancer: which to choose. Lung Cancer 2001; 31: 31-36.

25. Maier A, Tomaselli F, Matzi V, et al. Comparison of 5aminolaevulinic acid and prophyrin photosensitization for photodynamic therapy of malignant bronchial stenosis: a clinical pilot study. Lasers Surg Med 2002; 30: 12-17.

26. Mathur PN, Edell E, Sutedja T, Vergnon JM. Treatment of early stage non small cell lung cancer. Chest 2003; 123: 17651805.

27. Kanaka C, Usuda J, Kato H. Pre operative photodynamic therapy for lung cancer (abstract). Nippon Ishinkin Gakkai Zasshi 2000; 101: 486-489.

28. Herth F, Becker HD, LoCicero J, Ernst A. Endobronchial ultrasound in therapeutic bronchoscopy. Eur Respir J 2002; 20: $118-121$

29. Lam S, Kennedy $\mathrm{T}$, Unger $\mathrm{M}$, et al. Localization of bronchial intraepithelial neoplastic lesions by fluorescence bronchoscopy. Chest 1998; 113: 696-702.

30. Radu A, Grosjean P, Fontolliet $\mathrm{CH}$, et al. Photodynamic therapy for 101 early cancers of the upper aerodigestive tract, the esophagus, and the bronchi: a single-institution experience. Diagnostic and Therapeutic Endoscopy 1999; 5: 145154. 